\title{
LA NOCIÓN DE SOBERANÍA EN LAS PROPUESTAS BOLIVIANAS PARA LA SALIDA AL MAR: EL CASO ARICA TRINACIONAL*
}

\author{
THE NOTION OF SOVEREIGNTY IN THE BOLIVIAN PROPOSALS \\ FOR ACCESS TO THE OCEAN: THE TRI-NATIONAL ARICA CASE
}

\author{
Cristián Ovando Santana**
}

\begin{abstract}
Este artículo profundiza en la noción de soberanía que está implícita en algunas propuestas bolivianas para la salida soberana al mar. Particularmente se adentra en las que reflexionan acerca de la discusión de una soberanía compartida como premisa clave para construir una zona trinacional de desarrollo, que comprenda el norte de Chile, el sur del Perú y el oeste boliviano. Para interpretar estas propuestas, la contribución se detiene en el desarrollo teórico de la noción de soberanía desde algunos aportes de la teoría de las relaciones internacionales. Se enfatiza en los aportes reflectivistas de la disciplina, pues son los que posibilitan cuestionar la noción de soberanía tradicional y abrirnos a nuevas posibilidades en la siempre compleja delimitación espacial del Estado.

Palabras clave: Teoría de las relaciones internacionales reflectivistas, Chile/Bolivia, soberanía del Estado, soberanía compartida.
\end{abstract}

This article examines the notion of implied sovereignty in select Bolivian proposals for a sovereign access to the ocean. Particular attention is given to proposals that reflect on the discussion of shared sovereignty as a key premise in building a tri-national zone of development, which includes the north of Chile, the south of Peru and the west of Bolivia. To interpret these proposals, the contribution focuses on the theoretical development of the sovereignty notion with inputs from theory of international relationships. It emphasizes reflectivist contributions to the discipline that allow questions regarding the traditional notion of sovereignty and new possibilities in the complex spatial delimitation of the State.

Key words: Reflectivist theories of International Relations, Chile/ Bolivia, Sovereignty of the State, shared sovereignty.

\section{Introducción}

En las interpretaciones de las nociones de soberanía estatal, que han adoptado los sucesivos gobiernos en el poder de Chile y Bolivia, siguen teniendo una gran influencia los postulados tradicional-realistas de la teoría de las relaciones internacionales. Sobre todo teniendo en cuenta el conflicto diplomático que mantienen desde fines del siglo XIX. En el caso de Chile ha sido una visión uniforme y naturalizada, basada en una irrestricta noción de integridad territorial que se expresa en los límites fronterizos resultantes de la guerra del Pacifico ${ }^{1}$, momento fundacional en que se definen los contornos del espacio oficial del Estado, coincidentes con la consolidación de la identidad nacional chilena (Fernandois, 2005).

No obstante, en el caso boliviano, si bien siguió el mismo periplo de Chile en cuanto a la construcción de sus fronteras definitivas, en las últimas tres décadas se han recogido ciertos debates jurídicos y politológicos que abren la posibilidad de construir nociones alternativas de soberanía. Estas giran en torno a la idea de una potestad compartida por ambos, acerca de territorios bolivianos anexados por Chile como consecuencia de la guerra del Pacífico, a partir de la injerencia de varios actores que cuestionan la territorialidad del Estado. Estas posturas se abren hacia subjetividades no estatales, como es el caso de grupos étnicos, elites económicas y gobiernos subnacionales, quienes propician "otras voluntades de desterritorialización" (Cornago, 2013), que con su práctica cuestionan los límites espaciales del Estado soberano. Estas posturas son recogidas por unos cuantos intelectuales, políticos y diplomáticos bolivianos, quienes buscan con sus propuestas un mayor entendimiento con sus pares chilenos para poder resolver el conflicto en torno

\footnotetext{
* Resultado Proyecto Anillos SOC 1109, CONICYT: "Relaciones transfronterizas entre Bolivia y Chile: Paradiplomacia y prácticas sociales 1904-2004".

** Universidad Arturo Prat, Instituto de Estudios Internacionales. Iquique, Chile. Correo electrónico: covando@unap.cl.
} 
a la mediterraneidad o enclaustramiento derivado de la guerra del Pacífico a partir de proyectos de desarrollo trinacional, pues se toma en cuenta la posición del Perú, al tenor del Tratado de 1929.

Si bien resultan comprensibles las posturas de ambos países: la chilena de un férreo statu quo, en tanto esa ha sido la invariable tendencia de su política exterior, pese a la existencia de matices ${ }^{2}$, y la boliviana que se abre a nuevas posibilidades, pues lo que pretenden es entregar propuestas innovadoras que incidan en los contenidos de la política exterior de su país respecto de la reivindicación marítima, estimamos que interpretar estas últimas bajo el lente de teorías de las relaciones internacionales que den cuenta de un debate crítico concerniente a la noción tradicional de soberanía, es relevante si pretendemos profundizar en las relaciones chileno bolivianas desde lecturas que cuestionen la primacía del Estado como único agente diplomático autorizado a participar en la arena internacional.

Es cierto que durante el siglo pasado se firmaron numerosos e importantes acuerdos bilaterales -desde el Tratado de 1904 hasta el Acuerdo de Cooperación Económica de 1994con el objetivo de resolver de forma pacífica y diplomática su litigio permanente (Carrasco, 1991; Bustos, 2004). Se cuentan además las Convenciones Sobre Tránsito de 1912 y 1937, la Declaración de Arica de 1953, los Acuerdos de Complementación Económica de 1955, la Cuestión del Lauca de 1962, el frustrado Abrazo de Charaña de 1978, junto a la vigente hasta hace algunos años agenda de 13 puntos que contempla un "diálogo sin exclusiones"3. En muchas de ellas la noción de soberanía tuvo un trato invariable en donde lo que se negociaba eran concesiones económicas y facilitación al libre tránsito al tenor del Tratado de 1904. No obstante, en algunos episodios -que no tienen una proyección lineal en la historia de la política exterior de ambos países, y que más bien son pequeñas inflexiones de carácter accidental en el devenir histórico- (ver Huysmans, 2005), y por tanto poco destacadas por la historia oficial- se han discutido acercamientos entre ambas autoridades fundados en visiones compartidas de soberanía.

Por lo demás, en los mejores momentos de la relación chileno boliviana (v. gr: en la década dorada de 1950 y en el "Abrazo de Charaña") las conversaciones diplomáticas parecían anticipar una solución viable al litigio mediante un canje territorial o por algún recurso (agua del lago Titicaca para irrigar la pampa del Tamarugal), o a la creación de un paso terrestre y marítimo para Bolivia. Pero estos proyectos fueron diseñados desde las sedes de gobierno, sin ninguna consideración con la realidad de las condiciones socioeconómicas, políticas y territoriales de las áreas epicentro del litigio. Por ello, una de las variables que se destacan en las propuestas bolivianas de soberanía compartida es la visión que tienen los territorios (regiones y departamentos), epicentros del litigio, a partir de sus potencialidades resultantes de una mirada del desarrollo regional trinacional. No obstante, a pesar de algunos progresos menores producidos por esos intentos, el espectro de la guerra del Pacífico continúa instalado en el imaginario colectivo del nacionalismo chileno y boliviano -particularmente entre aquellas élites políticas y militares que viven en Santiago de Chile y La Paz-, lo que impregna de desconfianza mutua, incluso un siglo después, el clima emocional en el que estas conversaciones diplomáticas formales se desarrollan rutinariamente (Francisco, 2009).

Con todo, el objetivo de este trabajo consiste en interpretar, bajo el lente de las teorías de las relaciones internacionales reflectivistas (Salomón, 2002; Del Arenal, 2014), la noción de soberanía que recoge el debate boliviano acerca del término del enclaustramiento marítimo a partir de relativizar la noción tradicional de la misma, apelando a una soberanía compartida como eje de la negociación entre los Estados de Bolivia y Chile.

En cuanto a los aspectos metodológicos, utilizaremos un procedimiento de estudio basado en registros dispares del pasado (Cornago, 2013; Huysmans, 2003), que intentan desentrañar el modo en que distintas formas de pensar la soberanía se han ido desplegando a lo largo del tiempo, teniendo en cuenta cómo ha llegado a ser lo que es hoy la mirada que se tiene pertinente al tema. Para ello debemos tener en cuenta las prácticas transfronterizas presentes en distintos momentos entre Chile y Bolivia; cómo ha sido el intento de construir regiones transfronterizas entre estas sociedades y las ideas en torno a la soberanía compartida. En este intento de genealogía interpretaremos la historia de la soberanía a partir de los significados de las discontinuidades y eventos accidentales en lugar de entenderlo como un continuo despliegue de un determinado telos (Huysmans, 2003). 


\section{La noción de soberanía desde la teoría de las relaciones internacionales}

La noción de soberanía constituye una categoría clave del debate propio de la teoría de las relaciones internacionales. Su definición canónica hace alusión a que "la superficie de la tierra debe ser dividida en unidades territoriales discretas, cada una con un gobierno que ejerza autoridad sustancial dentro de su territorio" (Murphy, 1996: 81) y que, junto a ello, dicha autoridad debe defenderla de las contingencias venidas del exterior. Esta noción es esencial por su carácter fundacional, en torno a la idea de que la soberanía estatal es la unidad estructural básica de la sociedad internacional (Bull, 1977). Esta sociedad internacional surge en el siglo XVII con la creación de unidades políticas estatales secularizadas que se consolidan desde la paz de Westfalia en 1648. En este periplo la soberanía se consolida como "una norma asentada" de las relaciones internacionales (Espósito, 1997: 191). Desde esta premisa se cimenta la noción realista que está representada por la existencia de "un poder centralizado que ejerce su autoridad legislativa y ejecutiva dentro de un cierto territorio" (Morgenthau, 1967, p. 299), que a su vez supone la existencia paralela de un contexto internacional anárquico, caracterizado por la imagen "de un mundo social donde la principal amenaza a la vida, la libertad y la felicidad de los individuos proviene de afuera, donde una sociedad bien regulada necesita ser protegida de incursiones externas por el poder del soberano" (Espósito, 1997: 191).

Surge así la soberanía como "un crucial mito de origen moderno" (Walker, 1995, Osiander, 2001), que permite sostener la legitimidad de Estado a partir de mantener a salvo a las unidades políticas de la anarquía reinante en el sistema internacional y de sus consecuentes contingencias. En respuesta a este mito y como contrapartida para este mismo autor soberanía también sería una "práctica, (...) que está haciéndose o deshaciéndose constantemente tanto en los intersticios de la vida diaria como también en los rituales de la pompa y el Estado" (Walker, 1995: 67).

En suma, la soberanía constituye la piedra angular del debate, pues su condición de potestad absoluta del Estado para cautelar a la sociedad de la anarquía reinante y de las contingencias de la vida, aunque no lo sea cabalmente, "es la suposición subyacente que designa las relaciones internacionales como un campo de estudio separado. Por tanto, si se pone en duda dicha potestad y exclusividad, supone que la naturaleza de la soberanía permanece profundamente enigmática (Nane, 2004: 30). ¿Es posible la existencia de otras voluntades a la estatal involucradas en la construcción de la soberanía? ¿Las eventuales ideas y prácticas de estos actores pueden modificar el contenido de la soberanía? ¿Han existido instancias que pongan en evidencia otras posibilidades de soberanía distintas a la definición canónica?

Como hemos dicho someramente, su existencia original planteó una solución moderna al dilema de la universalidad y particularidad que enfrentó a las sociedades desde Westfalia (Walker, 1993). No obstante, para este mismo autor, "la soberanía no es un principio permanente de orden político; la apariencia de permanencia es simplemente un efecto de prácticas complejas que operan para afirmar continuidades y para marginar las rupturas y los peligros". (Walker, 1993: 161). Estas rupturas o transgresiones siempre han existido desde la modernidad, pese a su ocultamiento. Es el caso de la territorialidad o la forma de concebir el territorio -sus propios contornos o fronteras- a que apelan y reivindican ciertos grupos dentro de un Estado-Nación o pertenecientes a distintos Estados debido a que comparten lengua, tradiciones; en definitiva, una identidad. Esta territorialidad tiene la particularidad que en ocasiones excede los contornos particulares que delimitan espacialmente la soberanía de dicho Estado.

En suma, una de las críticas más potentes de la noción tradicional-realista de la soberanía proviene de las teorías reflectivistas (Salomón, 2002; De Arenal, 2014). Particularmente el posestructuralismo apunta a que en la definición de la naturaleza, extensión y características de las unidades territoriales -en las cuales se ejerce la autoridad soberana de los Estadosse debe tomar en cuenta el proceso social que toma lugar en aquellas, aun cuando esto suponga desafiar la noción de unidades territoriales discretas con una autoridad sustancial acerca de dicho territorio, ya que esta aproximación considera que las fronteras que demarcan las comunidades domésticas no son naturalmente dadas, indudables ni permanentes. "Las fronteras son traspasadas tanto por grupos domésticos excluidos por el Estado (los privados de derechos civiles, sean minorías, desamparados o criminales, por ejemplo) como también grupos externos (como refugiados y extranjeros ilegales). Estas transgresiones, tomadas en su conjunto, 
hacen difícil imaginar no solo las fronteras sino también los espacios domésticos como opuestos a los internacionales" (Weber, 1995: 109).

Desde esta perspectiva se replantean las formas tradicionales de pensar el vínculo entre Estado, territorio y nación, porque, al analizar el desarrollo del Estado moderno y su configuración espacial desde el punto de vista genealógico, se constatan tendencias contradictorias entre dimensiones políticas, sociales y culturales, cuestionando su capacidad para representar la totalidad del espacio. Con todo, desde este giro espacial se cuestionan las representaciones identitarias ancladas en la soberanía territorial. Más bien se identifica la conformación de estas identidades a partir de redes múltiples (Appadurai: 2003), más allá de los Estados.

En suma, la inscripción de los límites espaciales del Estado soberano es un tema que se debe reconsiderar, toda vez que "constituye un acto político de primer orden en la producción de aquella subjetividad que, se diría, habilita para participar plenamente en la vida internacional" (Cornago, 2013: 19). Por ello, para esta postura, la inscripción o definición de esos límites variará según el contenido de dicho proceso social, pues cada actor porta su propia subjetividad con arreglo a estos límites.

\section{Algunos aportes reflectivistas al debate de la teoría de las relaciones internacionales respecto de soberanía}

Las familias reflectivistas -constructivismo radical y posestructuralismo (Del Arenal, 2014)reflexionan, entre otras materias, acerca del problema de la subjetividad en la constitución de los actores internacionales. Particularmente abordan la posibilidad de la existencia de una pluralidad de identidades colectivas y formas de subjetividad distinta a la estatal, pero que conviven con aquella de forma compleja en la escena internacional, en la medida que su existencia problematiza "la pretensión de establecer divisiones objetivas a base de los criterios territoriales asociados a la soberanía del Estado" (Cornago, 203: 19-20).

Esta subjetividad que porta cada actor deriva de la competencia entre narrativas pertinente a la realidad internacional y las relaciones de poder que estos discursos implican y esconden (Der Derian, 1987; Smith, 1995; Walker, 1995). Desde esta perspectiva, además, algunas narrativas hegemónicas -Estadocéntricas-han impuesto nociones de anarquía, soberanía, seguridad nacional, entendidos como atributos permanentes, dados y naturalizados del sistema internacional, blindando a las relaciones internacionales de pensamientos alternativos (Herranz, 2009). Esta aproximación plantea salir de estas categorías universales, porque desconfía de aproximaciones que pretendan encontrar verdades universales, una propuesta incompatible con la búsqueda de "alteridad", pluralidad y diversidad en todas las dimensiones de la vida social (Salomón, 2001: 29). Desde esta consideración, "las relaciones internacionales no son sino una forma particular de las relaciones sociales que los contornos del Estado difícilmente pueden contener" (Cornago, 2013: 20).

En este intento de evidenciar la existencia de pluralidad en las dimensiones más relevantes de las relaciones internacionales -donde la noción de soberanía es clave-, "el posestructuralismo se emplea a fondo en identificar los espacios de contestación teórico-práctica que puedan impulsar la democracia, la ciudadanía, o la reconciliación, más allá de los corsés establecidos por la soberanía del Estado, promoviendo la comprensión de nuevas formas de subjetividad política..." (Cornago, 2013: 22). En concreto, "la adopción de esa nueva política supone una resistencia a las prácticas del Estado así como un rechazo a los discursos teóricos que lo sostienen, y que pretenden contener todas las formas de subjetividad y de expresión... (Cornago, 2013: 22).

Siguiendo esta argumentación, en referencia con nuestro problema de investigación, buscar mayor entendimiento desde la alteridad y con ello intentar solucionar el largo conflicto diplomático por el enclaustramiento boliviano surgiría desde estas premisas, sobre todo a partir de rastrear discursos respecto de temas vecinales que relativicen dogmas irrestrictos de soberanía, frontera e integridad territorial, en la medida que se tratarían de categorías justificadas y legitimadas por los Estados.

En suma, a partir de una disputa de discursos es posible cotejar la persistencia de distintas identidades políticas con proyección internacional que conviven con la identidad nacional (identidad regional, transfronteriza, entre otras) y que reivindican eventualmente su propia noción de soberanía y territorialidad.

\section{Espacialidad y subjetividades}

Finalmente, es un lugar común en los debates actuales propios de las relaciones internacionales 
señalar que la interdependencia entre las sociedades ha rediseñado las fronteras históricas, junto con que la interdependencia creciente y la globalización implican relativizar la importancia del Estado, ampliando la variedad de los llamados actores no estatales que participan en la internacionalización de las regiones vía integración transfronteriza. No obstante, como hemos venido señalando desde inicio de artículo, desde el posestructuralismo, la lectura es más profunda, pues la redefinición "de los límites espaciales del Estado soberano constituye un acto político de primer orden en la producción de aquella subjetividad que, se diría, habilita para participar plenamente en la vida internacional" (Cornago, 2013: 19) y transfronteriza. Este giro teórico implica que, a la vez que las fronteras se encuentran involucradas en nuevos movimientos y dinámicas territoriales, también en ellas perviven otros movimientos y dinámicas antiguas, en la medida que las fronteras que demarcan las comunidades domésticas no son naturalmente dadas, indudables ni permanentes, toda vez que están sujetas a varias transgresiones (Weber, 1995: 109).

Por tanto, la soberanía del Estado, que define las fronteras físicas de los Estados con la pretensión de que sea de una vez y para siempre, es "un elemento delimitador tan importante como inestable, pues como hemos dicho la territorialización a la que aspira nunca es completa. Aunque las políticas de contención territorial $^{4}$ (Haesbaert, 2013, 13, 14), que han afectado a dichas subjetividades han sido una constante en la historia diplomática.

En el antagonismo entre distintas subjetividades con proyección internacional "se encuentra la tensión constitutiva de la vida internacional, que impone la readaptación constante (...) de la realidad del Estado a las configuraciones diversas que en cada momento y en cada lugar adopta esa tensión (Cornago, 2013: 19).

\section{La noción de soberanía en algunas propuestas bolivianas para la salida al mar: el caso de Arica Trinacional}

Discutido el marco teórico de la noción de soberanía reflectivista, a continuación cotejaremos estos postulados con algunas propuestas bolivianas, junto con la percepción de soberanía de algunos sujetos históricos concretos que habitaron la región transfronteriza de Tarapacá, actual Arica y Parinacota, particularmente los que abogan por cierta "alteridad" paraestatal. Para ello, destacaremos algunas fuentes, trabajos e investigaciones bolivianas y chilenas, particularmente en cuanto a las últimas, destacando algunas regionales.

Aunque el imaginario nacional del extremo norte ariqueño fue potente en las décadas posteriores a la posguerra del Pacífico (Díaz et al., 2012, 2014; Galdames, et al., 2007, 2014), con todo lo que implicó en cuanto a las aprehensiones territoriales hacia las fronteras contiguas, sobre todo a partir de la chilenización de aquellos (Díaz 2003; Morong y Sánchez, 2006) en este periodo también encontramos desperdigadamente en la historia de las relaciones chileno bolivianas otras subjetividades y percepciones respecto de cómo entender la soberanía, y de paso excepcionalmente encontramos intentos de solucionar la mediterraneidad de este último a partir de discutir la noción de soberanía que oriente las relaciones entre ambos. Se trata, desde el punto de vista genealógico, de acontecimientos accidentales del devenir histórico de estos países, acontecimientos singulares fuera de cualquier finalidad monótona de la historia que vincula a ambas sociedades (J. Huysmans, 2005).

Ya terminada la guerra, la mayor preocupación era la disputa diplomática por la titularidad de la soberanía de Arica, ciudad situada en el extremo de la provincia de Tarapacá, anexada por Chile como resultado del conflicto bélico. Respecto de ella se comenzaron a elaborar tantas posibilidades como la imaginación lo permitía. Entonces surgió la idea del presidente Leguía de una administración conjunta de Arica por Perú y Chile, dejando explícitamente fuera a Bolivia (González, 2006: 108 y ss.). Esta idea era inaceptable para un país como Chile donde el Estado-Nación era entonces, como ahora, firme y centralista, no obstante deja entrever otras posibilidades, que en el siglo XX se desarrollan con mayor sistematicidad.

Otro de los antecedentes que nos permite hacer una interpretación pertinente a una percepción local distinta a la nacional respecto de la noción de soberanía, fue la dinámica transfronteriza que acontece en Tarapacá en la "Sociedad del Salitre" vinculada a las migraciones y a los habitantes que construían la pampa, sobre todo desde la perspectiva de las transgresiones a la soberanía nacional a partir de sus propias subjetividades territoriales, pese a la preeminencia soberanía chilena dictada desde el Estado central: 
“...Los obreros bolivianos llegaron a trabajar a las salitreras de Tarapacá, primero bajo el amparo de un Pacto de Tregua y luego de un Tratado de Paz y Amistad, pero sobre todo lo hicieron bajo el amparo de los propios empresarios del salitre que requerían mano de obra para las faenas de extracción y elaboración del nitrato. De esta manera se generó una movilidad transfronteriza compleja, tanto por los flujos de bienes y personas como por las dimensiones culturales de la misma. La importancia de esta migración fue tal que, unido al origen peruano de esta provincia, se puede decir que durante el período salitrero, desde un punto de vista demográfico, Tarapacá fue un territorio sociológicamente trinacional: peruano, boliviano y chileno, pero bajo un estado de derecho y soberanía chileno" (González, 2009: 79).

Junto con constituirse Tarapacá como región cosmopolita a partir del Ciclo del Salitre (González, 2009), sus históricas propuestas de desarrollo endógeno sustentadas en un marco geográfico transfronterizo y un discurso regionalista (Castro, 2003, 2005) han influido en esta visión de soberanía. En efecto, por ejemplo, agentes diplomáticos chilenos y bolivianos afincados en las provincias chilenas de de Tarapacá, Arica y La Paz, respectivamente (en 1903 y 1920), buscaban con sus contactos, sobre todo comerciales y en vista al desarrollo de conexiones transfronterizas, compatibilizar intereses y un mayor entendimiento desde la validación de los parámetros regionales, como la idea de "frontera abierta", en conjunto con los conceptos derivados desde las respectivas capitales, tal como el de "límites fronterizos nacionales" (Castro, 2003b: 7-8).

Ya en la década de $1960^{5}$, al amparo de las políticas desarrollistas de fomento al desarrollo regional del Norte Grande y particularmente de Arica (Pizarro y Ríos, 2010), las demandas ciudadanas ariqueñas por el Puerto Libre, la Junta de Adelanto y el Plan Andino ${ }^{6}$ ponen en evidencia que desde ellas se desprendía una visión particular del espacio que contendría las históricas dinámicas transfronterizas con referencia a lo andino (Ovando y González, 2014: 56-58), incidiendo en la apertura de los contornos del Estado-Nación de manera inédita. En efecto, "La Junta de Adelanto de Arica", como señala un documento de la época:

\begin{abstract}
"Desde su creación ha estado sosteniendo el significado macizo de su ubicación geográfica, de sus áreas de influencia, y la necesidad de su aprovechamiento para beneficios regional y nacional. La firma del Pacto Andino le da ahora valor formal a tal pragmatismo.

Arica es la puerta de salida de una vasta región de la cuenca interior de América Latina. Lo fue desde la época de la Colonia, cuando la plata de los Lípez se embarcaba por Arica y cuando el azogue para su tratamiento se descargaba en ella.

Lo es desde que el F.C. de Arica a La Paz, en su época, era la vía más corta del Pacífico a Bolivia. Lo es, ahora, con la próxima terminación del camino internacional de Arica a la frontera boliviana. Lo es también por la integración cotidiana y forzada con el Depto. de Tacna, establecida por el Tratado de 1929 con el Perú. Lo es con el oleoducto Sica Sica / Arica, que permite el embarque de petróleo del oriente boliviano por el Pacífico. Lo será por la extensión de la red caminera y ferroviaria de Bolivia a Santos (Brasil), por Corumbá" (Enciclopedias regionales 1972: 82).
\end{abstract}

A su vez, esta perspectiva no es ajena a la discusión ideológica -desarrollista- de los primeros años de la década de 1970, de la que fue expresión el Plan Andino. Algunos intelectuales y académicos se sintieron llamados a participar en este proyecto político de desarrollo transfronterizo: especialmente John Murra tendrá influencia intelectual entre sus pares de la Universidad del Norte y en la propia Junta de Adelanto de Arica (Galdames y Ruz 2010; Galdames, 2005), debido a su innovador enfoque de interpretación de la economía andina. La discusión teórica acerca del desarrollo, donde lo andino comenzaba a ocupar un espacio relevante en estas regiones y también en el marco político e ideológico de la época (Ovando y González, 2014: 56-58) influyó, conjeturamos, en la disputa legítima respecto de lo que constituye una demarcación autorizada de los contornos de la comunidad política de la época.

En cuanto a las propuestas bolivianas, ya en este $\operatorname{siglo}^{7}$, entre los intelectuales bolivianos que reivindican otras formas de entender la noción de soberanía para orientar el diálogo entre ambas sociedades, y así poder demandar 
la recuperación de la salida al mar para Bolivia, podríamos mencionar a Ricardo Anaya (pág. 72 y ss.) y su Arica Trinacional, junto a Antonio Araníbar y su esfuerzo por superar el concepto de soberanía absoluta. En cuanto al primero, su propuesta de Arica Trinacional se basa "en el concepto de integración, paz y desarrollo entre los países involucrados en la guerra del Pacífico, mediante la internacionalización de Arica, donde se crearía un polo de desarrollo compartido por Chile, Bolivia y Perú" (Pareja, 2013). Se puede interpretar que lo que busca el autor es construir regiones asociativas. Siguiendo a Sergio Boisier, estas "se conforman mediante acuerdos estratégicos y tácticos entre dos o más regiones contiguas, a fin de posicionar mejor tales espacios" (González, 2006: 124), sobre todo debido a su posición geográfica de cara al Pacífico y como región logística para conectarse al centro oeste del subcontinente, en vista de los corredores bioceánicos. Continúa el autor señalando que estos "acuerdos deben ser democráticamente sancionados para conferir a la región asociativa una permanencia en el largo plazo" (González, 2006: 124). Este se trataría de un elemento clave desde la teoría desarrollada en apartado anterior, ya que el posestructuralismo intenta buscar la pluralidad de visiones en torno a la soberanía a partir de identificar los espacios de contestación y reivindicación teórico-práctica que puedan impulsar la democracia, la ciudadanía ante el Estado y su visión tradicional de soberanía.

Con todo, la pregunta que se planeta Anaya es si entre Bolivia, Perú y Chile existe o puede existir una Región Asociativa de Frontera (RAF). Es clave tener en cuenta en su propuesta que las transgresiones a la soberanía absoluta, surgidas desde los actores regionales del desarrollo, son el fundamento de la noción de soberanía compartida y no lo que dictan las capitales en cuanto a la demarcación espacial de los límites. También esta propuesta se introduce en la discusión de las soberanías perforadas, siguiendo a Panayotis Soldatos, para demostrar que se "remite parte importante de la perforación de la soberanía a los actores subnacionales, que emanan de las regiones, de las ciudades, y de sectores específicos de la administración del Estado en su esfuerzo por internacionalizarse..." (Witker 2004: 82). Es decir, las acciones de actores subnacionales como las comunidades de Tarapacá, Arica, Tacna y Oruro, en su afán de integrarse físicamente, pueden constituirse en factores que permitan la emergencia de una nueva geopolítica que, a su vez, abra el entendimiento bilateral sobre la base de la revisión del concepto tradicional de soberanía a partir del reconocimiento de dichas transgresiones 8 .

Es importante destacar algunas precisiones respecto de su propuesta de 1979. Primero: "La ‘internacionalización' es una figura jurídica en virtud de la cual ninguno de los países que la admiten ejerce soberanía absoluta en el territorio internacionalizado, sino, por el contrario, dicha soberanía es compartida por los países que pacten esta cosoberanía, por medio de un Código Constitutivo de derechos y deberes y organización de un aparato administrativo" (Pareja, 2013). Para Anaya, "el Código Constitutivo debería calificar el área trinacional (Arica) como área de paz, integración, y desarrollo, y debe estar precedida por un estudio económico, social, político y cultural del Área Trinacional, comprendida entre los grados 17 y 19 de latitud sud, con una extensión de costa marítima de 227 kilómetros, y una superficie de 15.450 kilómetros cuadrados (Pareja, 2013).

En cuanto a destrabarse del lastre de la soberanía tradicional, esta propuesta de Arica trinacional sugiere que a partir de construir una región transfronteriza desde el punto de vista económico, la soberanía mostraría propiedades contradictorias precisamente porque no es algo absoluto, sino es absolutamente necesaria para el funcionamiento del mercado (Nane, 2004: 30). Se trataría de un mercado trinacional que necesariamente requiere de Estados -las partes- que negocien la forma y el contenido de la soberanía, cuestión que evidencia por qué la noción de aquella necesariamente asume una forma tan enigmática en las relaciones internacionales" (Nane, 2004: 30)

En suma, la propuesta de Anaya supone que, a partir de un territorio trinacional con soberanía compartida delimitado en referencia al quehacer y aspiraciones de sus habitantes, "Paz y desarrollo (...) pueden armonizarse en Área de integración donde, Bolivia y Perú dejando atrás resentimientos justificados pero infecundos, y Chile arrogancias innobles, conjuguen esfuerzos para brindar a la región disputada y hoy atrasada del Pacífico, progreso y bienestar que a su vez contribuyan al mejoramiento integral de las naciones pactantes" (Anaya: 1987: 237).

Finalmente, con carácter económico, la propuesta de Anaya probablemmte se haya inspirado "por el desarrollo relativo que tuvo Arica en la década de los años sesenta y parte de los setenta, respecto de 
las demás ciudades de la subregión, incluyendo a Tacna, Iquique y La Paz. En esa época todavía no se conocía la experiencia europea de integración económica" (González, 2007: 124).

Además, Antonio Araníbar destaca por su propuesta: Enfoque Trinacional de Beneficios Mutuos. Transcribimos algunos párrafos de su propuesta que dejan entrever la noción de soberanía a que comparte. Señala, apelando primero a las elites y a la contestación ciudadana hacia ellas:

"La posibilidad de estructurar una opción cooperativa entre Chile, Bolivia y Perú depende en alto grado de las decisiones políticas que sus Estados sean capaces de adoptar, con el respaldo de sus respectivas sociedades nacionales, en la perspectiva del diálogo y el consenso trinacionales orientados al desarrollo sostenible e integrado de los tres países vía la creación de una plataforma conjunta hacia la cuenca del pacífico, con beneficios reales y tangibles para todos y con mejoramiento de la calidad y las condiciones de participación y presencia de Bolivia en el océano pacífico. Dichas decisiones podrán surgir en la medida que sus elites dirigentes sean capaces de superar y promuevan activamente la superación de percepciones y la remoción de obstáculos, conceptuales y fácticos, acumulados a lo largo de una historia de confrontaciones" (Araníbar, 2002: 207).

A continuación, señala enfáticamente en el rol de las sociedades civiles regionales, en un claro guiño a las propuestas reflectivistas en lo referido a que el posestructuralismo intenta buscar la pluralidad de visiones en torno a la soberanía a partir de identificar los espacios de contestación y reivindicación teórico-práctica que puedan impulsar la democracia, la ciudadanía ante el Estado:

"El segundo paso es que, muñidos de esa convicción y dotándola de sustancia práctica (mediante vivencias, experiencias, estudios y propuestas) que vayan mostrando la seriedad y la conveniencia del mismo para todos los convocados, los bolivianos deberían promover todas las iniciativas posibles para desarrollar al máximo los vínculos entre las sociedades civiles y políticas de los tres países. Es decir, promover tanto a niveles oficiales como no oficiales; en eventos formales o informales; en temas políticos, económicos, culturales, sociales, religiosos o de otra índole el mayor involucramiento de la más amplia cantidad posible de actores individuales y colectivos, en la tarea del conocimiento o el reconocimiento mutuo, en el propósito de afinar acercamientos y precisar diferencias para hacer más comprensibles y tolerables estas y derivar de aquellas intereses y objetivos comunes" (Araníbar, 2002: 207).

Finalmente, sentencia, apelando a las historias comunes, particularmente las surgidas en las fronteras contiguas, aquellas que emprenden las transgresiones a la soberanía:

"Si ataduras hay, ellas se encuentran en las actitudes, en las percepciones, en los mitos que alimentan nuestro recelo. Pues bien, ese es el primer problema que pretendemos enfrentar y contribuir a superar. Para ello contamos, entre otras cosas pero quizás fundamentalmente, con el sustrato común de lazos cooperativos que (...) se han ido tejiendo entre nuestros tres pueblos y que, para sorpresa de los fundamentalistas de todos nuestros países, son mucho más amplios de lo que imaginamos en todos los niveles, comenzando desde el básico de los entrelazamientos familiares, pasando por el fundamental de los vínculos de trabajo, estudio, religión u otras actividades de socialización y rematando en los pequeños, medianos y grandes negocios, legítimos y de los otros (contrabando y narcotráfico), en que bolivianos, chilenos y peruanos nos hemos enfrascado debido a nuestra vecindad geográfica y nuestras afinidades culturales. Necesitamos incrementar el flujo de nuestros intercambios en el plano cultural y humano para conocernos mejor, valorarnos adecuadamente y superar así el rencor de unos y la indiferencia o soberbia de otros" (Araníbar, 2002: 211). 


\section{Consideraciones finales}

La idea de reivindicar una soberanía perforada, escindida o compartida, que plantean Anaya y Araníbar como paso previo para encontrar un futuro compartido entre los tres países (Araníbar, 199: 107-111), estimamos recoge los planteamientos de Cynthia Weber (1995) acerca de que no existe un concepto único ni homogéneo de soberanía. Para ella más bien la historia -su genealogía- nos muestra que son las elaboraciones discursivas las que plasman los contenidos de tales conceptos y de las prácticas políticas que la sustentan. En este sentido, para comprender cabalmente cómo se construye la soberanía en un momento dado, debemos tener en cuenta "las condiciones en las que en cada época y en cada lugar acontece la disputa respecto de lo que constituye una demarcación autorizada de los contornos de la comunidad política" (Bertelson, 1995).

Esa disputa, para nuestro caso, estuvo marcada por demandas regionales por el desarrollo transfronterizo hacia Bolivia, las que portaban su propia territorialidad que desafiaba y desafía hoy marginalmente la noción de soberanía tradicional. Como dijimos, desde ellas se desprende una visión particular del espacio que contendría las históricas dinámicas transfronterizas con referencia a lo andino.

Estas representaciones de la frontera y la soberanía, conjeturamos, influyeron en la disputa legítima acerca de lo que constituye una demarcación autorizada de los contornos de la comunidad política de la época, implicando un diálogo entre actores bolivianos y chilenos interesados en el desarrollo de esta subregión. Así, quienes interpretaron la naturaleza transfronteriza de la frontera y la soberanía en el Norte Grande en torno a Arica trinacional, teorizaron y lo siguen haciendo concerniente a aquellas, pues para este enfoque crítico, que relaciona teoría a práctica cotidiana, el estudioso y el actor social y político deliberan creando los eventos de las relaciones internacionales. Desde esta práctica adjuntaron esos significados a un fenómeno material (la demarcación del espacio), afectando la manera en que ellos y otros actores piensan de esta soberanía, creando así el tabú en relación cómo se entiende la soberanía, prevaleciendo la forma tradicional. Es importante destacar que si esa teorización como práctica impone determinadas subjetividades -como la que porta las soberanías nacionales en desmedro de quienes proponen una soberanía trinacional- se perpetúan relaciones de poder, en íntima relación con el saber, configurando un debate que pretendimos abrir.

Con todo, ¿qué formas de saber y hacer prevalecieron en el momento histórico que se concibió la transgresora estrategia Arica Trinacional?

La andina y la ciudadana, marcadas por la reivindicación de lo transfronterizo como una forma de sobrellevar el sentimiento de abandono que aquejaba al norte, incidiendo en la discusión de la noción de soberanía y desarrollo que primaba en la época, aun cuando su posibilidad práctica fuese desechada de plano.

En consecuencia, qué contenidos contemple una determinada noción de soberanía para así concebirla en la realidad, es un proceso de resultados variables que determina además su legitimidad (a quien representa). Pero lo más importante es que tendría repercusiones prácticas en lo referido a en qué supuestos es posible plantear la violación de la soberanía a partir de ciertas conductas (Weber, 2005) y también plantear -en nuestro caso- la legitimidad o no de la idea de administración compartida de un territorio por distintos Estados, como es el caso de Arica Trinacional.

Por tanto, la constante reelaboración de la noción de soberanía -a partir del poder político y sus ideologías- se reflejaría en sus prácticas políticas. Ejemplo de lo recién expuesto es la práctica política inédita que recoge Araníbar al plantear la idea de soberanía compartida propuesta por Perú para dar solución a la mediterraneidad boliviana:

"Es el Perú el que recoge el concepto, al plantear, como condición para ceder un corredor soberano a Bolivia al norte de Arica, el establecimiento en la provincia de Arica, a continuación del corredor, de una área territorial bajo soberanía compartida de los tres Estados, Perú, Bolivia y Chile". $\mathrm{Al}$ hacerlo se cuida de no dar definición sobre su contenido, la que, implícitamente, podría estar sujeta a negociación y, por tanto, al acuerdo y creatividad de las partes (Araníbar, 1999: 109). 


\section{Referencias Citadas}

Anaya, Ricardo

1987 Arica Trinacional: Bolivia, Chile y Perú. Editorial Lo amigos del libro, La Paz.

Appadurai, Arjun

2003 "Sovereignty whitout territoriality: Notes for a postnational geography. Cap. XVI. En Setha M. Low and Denise Lawrence Zúñiga (edits.) The antropology of space and place. Locating cultura. Blackwell publishing, pp. 337-350.

Araníbar, Antonio

2002 "Bolivia, Chile y Perú: Hacia un Futuro Compartido". Si Somos Americanos, vol. III, año 2.

Araníbar, Antonio

1999 "Bolivia, Chile y Perú: Hacia un Futuro Compartido" La Paz, Bolivia: Plural editores.

Bertelson, John

1995 A Genealogy of Sovereingty, Cambridge, Cambrdige University Press.

Bull, Hedley

1977 Order in World Politics, Londres, Macmillan.

Bustos, Carlos

2004 Chile y Bolivia: Un largo camino, Santiago, RII Editores

Carrasco, Sergio

1991 Historia de las relaciones chileno-bolivianas, Santiago, Editorial Universitaria

Castro, Luis

2003b "Un chileno en La Paz, varios bolivianos en Iquique: Ideas y visiones sobre la integración económica y las relaciones políticas entre Arica, Tarapacá y Bolivia (19031920)". Revista de Ciencias Sociales: 4-12.

Castro, Luis

2002 "El temprano regionalismo de los tarapaqueños durante el ciclo salitrero: de los discursos económicos a la identidad socio-cultural, 1880-1930”. Revista de Ciencias Sociales: 6-14.

Castro, Luis

2005 Regionalismo y desarrollo regional: debate público, proyectos económicos y actores locales (Tarapacá 18801930). Viña del Mar: CEIP Ediciones.

Castro, Luis

2005 b "Los ariqueños, el desarrollo regional y las propuestas del Comité Pro-resurgimiento de Arica, 1932" Diálogo Andino $\mathrm{N}^{\circ} 25$, pp. 77-99.

Cornago, Noé

2013 Breviario de postestructuralismo para internacionalistas, en: http://www.academia.edu/2286259/Breviario_de_postestructuralismo_para_internac Ionalistas.

Del Arenal, Celestino

2014 Relaciones Internacionales y Etnocentrisno, Tecnos, Madrid.

Der Derian, Jean

1987 On Diplomacy: A Genealogy of Western Estrangement. Oxford, Blackwell.

Díaz Araya, Alberto

2003 "Problemas y Perspectivas Sociohistóricas en el Norte Chileno: Análisis sobre la 'Chilenización' de Tacna y Arica”, Revista Si Somos Americanos de estudios fronterizos, Vol. 5, $\mathrm{N}^{\mathrm{o}} 4$, pp. 49-82.

Díaz Araya, Alberto; Ruz Zagal, Rodrigo; Galdames Rosas, Luis (compiladores)

2014 Tiempos Violentos. Fragmentos de Historia Social en Arica. Ediciones Universidad de Tarapacá. Arica, Chile.
Díaz Araya, Alberto; Ruz Zagal, Rodrigo; Galdames Rosas,

Luis y Tapia Tosetti, Alejandro

2012 El Arica peruano de ayer Siglo XIX. Atenea, No 505, pp. 159-184.

Editorial de Enciclopedias Regionales

1972 "Ensayo de información general del departamento de Arica", Enciclopedia de Arica, Santiago, auspicio de la Universidad de Chile.

Espósito, Carlos

1997 "Soberanía y ética en las relaciones internacionales: contextos superpuestos", Isegoría, № 16, 1997, pp. 189-199.

Fernandois, Joaquín

2005 "Mundo y fin de mundo: Chile en la política mundial 1900-2004". Santiago, Ediciones Universidad Católica de Chile

Francisco, Mila

2009 "La cuestión marítima en la política exterior de Chile y Bolivia”, Diplomacia, No 118, pp. 47-69.

Galdames, Luis y Rodrigo Ruz

2010 "La Junta de Adelanto de Arica y John V. Murra. Dos lecturas sobre el desarrollo andino en el norte de Chile", Chungará, Revista de antropología chilena, vol. $42, \mathrm{~N}^{\circ} 1$, pp. 257-270.

Galdames, Luis

2005 "El discurso del Estado a través de la creación del puerto libre de Arica: Aproximación semiológica", Diálogo Andino, $\mathrm{N}^{\circ}$ 26, pp. 9-14.

Galdames Rosas, Luis; Díaz Araya, Alberto

2007 La Construcción de la identidad ariqueña en las primeras décadas del Siglo XX. Revista Diálogo Andino $\mathrm{N}^{\circ} 29$, pp. 19-28.

Galdames Luis; Ruz, Rodrigo; Meza, Michel

2014 "Imaginario nacional en revistas de la frontera norte de chile post Guerra del Pacífico: ariqueña (Arica, 1923) y Torbellino (Tacna, 1924)" Interciencia, jul, vol. 39, No 7 , pp. 490-494.

González, Sergio

2006 Arica y la triple frontera. Integración y conflicto entre Bolivia, Perú y Chile, Iquique, Aríbalo.

González, Sergio

2009 "La presencia boliviana en la sociedad del salitre y la nueva definición de la frontera: auge y caída de una dinámica transfronteriza (Tarapacá 1880-1930) "Chungará vol. 41, $\mathrm{N}^{\mathrm{o}}$ 1, pp. 71-81.

González, Sergio y Ovando, Cristian

2011 La década dorada de las relaciones diplomáticas entre Chile y Bolivia T'inkazos, número 29, 2011, pp. 87-108.

Herranz, A

2009 "Muchos mundos, muchas Europas: el postmodernismo en las Relaciones Internacionales y los Estudios Europeos", en Documentos CIDOB, Dinámicas interculturales, Fundación CIDOB, Barcelona, 14: pp. 47-56.

Haesbaert, Rogerio

2013 "Del mito de la desterritorialización a la multiterritorialidad". Revista Cultura y Representaciones Sociales $\mathrm{N}^{\circ} 15$, pp. 9-41.

Huysmans, James

2005 "James Der Derian: the unbearable lightness of theory" in: Iver B.Neumann and Ole Wæver, The Future of International Relations. Masters in the Making?, Routledge, London, pp. 361-384. 
Morong, Germán y Sánchez, Eugenio

2006 Pensar en el Norte; la construcción historiográfica del espacio de frontera en el contexto de la chilenización 1883-1929. Revista Diálogo Andino No 27, pp. 95-112.

Murphy, Alexander B.

1996 "The Sovereign State System as Political-territorial Ideal: Historical and Contemporary Considerations". En Thomas J. Biersteker y Cynthia Weber (1996). State Sovereignty as Social Construct. New York, Cambridge University Press.

Nasi, Carlos (comp.)

1998 Postmodernismo y relaciones internacionales, Uniandes/ Universidad Nacional /Universidad Javeriana, Bogotá.

Orias, Ramiro

1997 "Derecho del mar y cooperación trinacional: una perspectiva boliviana" En: Raúl Barrios. Bolivia, Chile y Perú. Una opción cooperativa. La Paz, 1997; pp. 71-104

Osiander, A

2001 "Sovereignty, international relations and the Westphalian myth", International Organization, 55: 2.

Ovando, Cristián y González, Sergio

2012 "La política exterior chileno-boliviana en la década de 1950 mirada desde la región de Tarapacá”, Polis [En línea], 32 | 2012, Publicado el 30 agosto 2012, consultado el 04 diciembre 2014. URL: http://polis.revues.org/6662

Ovando, Cristián y González, Sergio

2014 La relación bilateral chileno-boliviana a partir de las demandas tarapaqueñas: aproximación teórica desde la paradiplomacia como heterología. Estud. int. (Santiago, en línea) [online]. 2014, vol. 46, No 177 [citado 2014-11-19], pp. 35-64. Disponible en: <http:// www.scielo.cl/scielo.php?script=sci_arttext\&pid=S0719$37692014000100002 \& \operatorname{lng}=e s \& n r m=i s o>$. ISSN 0719-3769. http://dx.doi.org/10.5354/0719-3769.2014.3086

Pareja, Antonio

2013 "Arica Trinacional" Los Tiempos, 5 de febrero de 2013.Disponible en: http://www.lostiempos.com/ diario/opiniones/columnistas/20130205/arica-trinacional_201193_429560.html.

Pizarro, Elías y Waldo, Ríos

2010 "Entre franquicias y beneficios: Una apuesta del Gobierno para el desarrollo regional de Arica (1953), en: Díaz, Alberto; Díaz, Alfonso; Pizarro, Elías (editores) (2010 Arica siglo XX: Historia y Sociedad en el extremo norte de Chile, Ediciones Universidad de Tarapacá, Arica pp. 79-94 Subcomisión de Desarrollo Social y Género del "Comité de Integración y Desarrollo Fronterizo entre la República de Perú y la República de Chile", Corporación Andina de Fomento -CAF y Corporación de Formación Laboral al Adolescente- CORFAL (2014) Manifiesto Dirigentes Vecinales Tacna y Arica (2014) Pachía, 18 de enero de 2014.
Rodrigues, Thiago

2013 "Agonismo y genealogía: hacia una analítica de las Relaciones Internacionales" Relaciones Internacionales, $\mathrm{N}^{\circ} 24$, oct. 2013. ISSN 16993950. Disponible en: $<$ http://www.relacionesinternacionales.info/ojs/index. php?journal=Relaciones_Internacionales $\&$ page $=$ article \&op=view\&path $\% 5 B \% 5 D=461>$. Fecha de acceso: 26 nov. 2014

Salazar, Fernando

2006 Bolivia y Chile: desatando nudos: propuesta de salida al mar para Bolivia, CERID- Plural, La Paz.

Smith, Steve

1995 "The Self-Images of a Discipline: "a Genealogy of International Relations Theory”, en K. Booth \& S. Smith, (eds.), International Relations Theory Today, Polity Press, Cambridge.

Salomón, Mónica

2002 "La Teoría de las Relaciones Internacionales en Los Albores del Siglo XXI: Diálogo, Disidencia, Aproximaciones", Revista Electrónica de Estudios Internacionales, № 4/. AEPDIRI. España. Disponible en: www.reei.org. [citado 2013-05-05].

Trafilaf, Sandra

2014 Diario UdeChile. Política: "Proponen crear un "espacio trinacional por la paz" en terreno en disputa limítrofe entre Chile y Perú", jueves 21 de agosto. Disponible en: http://radio. uchile.cl/2014/08/21/proponen-crear-un-espacio-trinacionalpor-la-paz-en-terreno-en-disputa-limitrofe-entre-chile-y-peru Concultado el 04-12-2014.

Walker, R.B.J

1995 "Relaciones internacionales y política mundial . En: "Nasi, Carlos (comp.): Postmodernismo y relaciones internacionales, Universidad Nacional, Bogotá, pp. 53-78.

Walker, R.B.J.

1993 Inside/Outside: Intemational Relations as Political Theory, Cambridge, Cambridge Unfversíty Press.

Weber, Cynthia

1995 Simulating Sovereignty. Intervention, the Suue and Symbolic Exchange, Cambridge, Cambridge University Press.

Weber, Cynthia

1995 Simulando Soberanía: Intervención, El Estado e intercambio simbólico. En: "Nasi, Carlos (comp.): Postmodernismo y relaciones internacionales, Universidad Nacional, Bogotá, pp. 85-115.

Witker, Iván

2007 "Mediterraneidad, soberanía y paradiplomacia: tres ejes de discusión teórica para la Problemática chileno-boliviana". Tapia, Marcela (Editora). Bolivia-Chile: Propuestas de integración para el siglo XXI. Inte-Unap/Gobierno Regional de Tarapacá, Iquique, Chile.
1 Estos se zanjaron con varios acuerdos: Tratado de Ancón de 1883, entre Perú y Chile, que estableció la soberanía de Chile en Tarapacá, región que es fronteriza con Bolivia, y la ocupación temporal de las provincias de Tacna y Arica, hasta que un plebiscito resolviera sus respectivas soberanías. 2 . Tratado de La Paz de 1904, que consolidó la paz y amistad entre Bolivia y Chile y la frontera bilateral definitiva. 3 . Tratado de Lima de 1929, que estableció la frontera entre Perú y Chile, conocida como Línea de la Concordia, demarcando en la cordillera el hito 80 entre ambas naciones y el hito 5 entre Bolivia y Chile, que establecen el punto tripartito, donde convergen los tres países. 
2 Respecto de matices en la política exterior chilena hacia Bolivia, consultar los alcances de "La época dorada de las relaciones chileno bolivianas" en: Ovando y González: 2012 y González y Ovando, 2011.

3 No obstante en 2012 y 2013 se han visto deterioradas las relaciones diplomáticas impactando las relaciones a nivel regional, ejemplo de ello ha sido la postergación indefinida por parte del gobierno boliviano del XIII Comité de Fronteras e Integración Chile-Bolivia, a realizarse en Iquique, Chile el 2013.

4 Contención territorial, entendido como un proceso contemporáneo de las relaciones de poder referidas al espacio, donde se dibujan nuevas-viejas estrategias de control territorial; y digo "nuevas-viejas", porque en nuestros días los muros son más visibles y evidentes que nunca, pero al mismo tiempo constituyen una estrategia muy antigua de construcción territorial (...). El territorio está vinculado siempre con el poder y con el control de procesos sociales mediante el control del espacio Haesbaert, 2013, 13).

5 Pizarro y Ríos (2010: 83), acudiendo a fuentes primarias y secundarias, constatan la percepción ariqueña de abandono de la región tras el Tratado del 29 y de preocupación estatal a partir de a mediados de la década de 1950: “...Para el diputado Alejandro Gallo parecía ser que el gobierno una vez libre del Problema del Pacífico haya manifestado poco interés por el adelanto del departamento (se refiere a Arica) y el bienestar de sus habitantes (Diario El Ferrocarril, 22 de febrero de 1932). La observación de Gallo es similar a la que sostiene el profesor Alfonso Díaz A., quien citando fuentes históricas relativas al período señala en un artículo que no se percibieron grandes cambios, tras la firma del tratado (1929) y que estos solo llegaron en la década del 50 con la creación del Puerto Libre y la Junta de Adelanto de Arica (1998: 130).

$6 \quad$ No obstante que estas demandas para Luis Castro (2005b: 87) se remontan con el mismo sentido regionalista y de una mirada transfronteriza a la década de 1930, a partir de una instancia ciudadana: "los ariqueños no solo deberán recordar a la Junta de Adelanto y sus miembros, sino que la memoria deberá extenderse hacia más atrás para darle su sitial al Comité Pro-Resurgimiento de Arica como al Intendente Antonio Subercaseux". similares apuntan a "vencer el escollo eme la tradicional visión de soberanía territorial" (Salazar, 2006: 130). En este punto señalan: "hoy sabemos que la soberanía de un Estado ya no es absoluta, sino más bien limitada y relativa" (Salazar, 2006: 131). Para Salazar esta constatación es resultado de un contexto internacional favorable que configura un nuevo paradigma de la política internacional, marcado por la democratización de los

sistemas políticos y la globalización. Desde esta premisa el autor propone una solución fundada en el concepto de supremacía territorial. Se define como "los derechos o competencias territoriales que un Estado posee respecto del territorio de un Estado extranjero". Para este autor el uso de esta práctica convencional en una eventual cesión de territorio a Bolivia no alteraría el patrimonio territorial o marítimo chileno, ya que, si bien se trata de la transferencia íntegra de competencias de un Estado a otro respecto de un territorio bajo la soberanía del Estado que la concede, no contempla cesión de soberanía plena, lo que conlleva disponer del mismo hacia terceros (144). Se trata de una franja territorial con supremacía boliviana al sur de la línea de la Concordia y al Norte de la ciudad de Arica.

Otro autor contemporáneo, Ramiro Orias (1997: 96-98), plantea la ceración de una Zona Especial de Desarrollo Trinacional, caracterizada por estar desmilitarizada y poseer una soberanía compartida. Plantea, además, la creación de una zona franca a Bolivia en territorio del norte chileno sin cesión de dominio territorial. También concibe la creación de una Zona de desarrollo Marino orientada por una política común (trinacional) de desarrollo marino (pág. 98).

8 Ejemplos de lo recién expuesto los encontramos al fragor de la demanda peruana en contra de Chile en La Haya: A propósito de la intención peruana de reconocer el triángulo terrestre como el nuevo límite, el Diario $U$ de Chile señala: "el historiador y economista, Luis Riveros, si bien destacó estar a favor de defender el territorio, y desaprobó la actitud del gobierno peruano, propuso terminar con estos conflictos territoriales, declarando este triángulo como un espacio trinacional, Bolivia, Perú y Chile. "No podemos seguir extendiendo estas disputas territoriales y creo que es mejor concentrarnos en los problemas de integración nacional y, en el caso chileno, concentrarnos en convertir efectivamente a Arica en un centro de integración trinacional, Bolivia, Perú y Chile. Creo que hemos perdido mucho el tiempo en eso, Arica está retrasada, particularmente respecto al crecimiento de Tacna y en gran medida es porque consideramos que estos temas todavía no están resueltos" (Trafilaf, 2014).

El otro ejemplo fue un un inédito encuentro entre "juntas de vecinos" de Tacna y Arica. Éstas, reunidas en Pachia, Tacna, redactaron el "Manifiesto Dirigentes Vecinales Tacna y Arica, Pachía, 18 de enero de 2014", en cuyas páginas se señala "Exigimos una política de Estado para la Integración Fronteriza, con una mirada local que fortalezca la convivencia" (2014: 1). También señalaron "Llamamos a seguir abriendo de espacios de integración”, más allá de dificultades, para así continuar el camino hacia el buen desarrollo de nuestras ciudades. 